\title{
La transformación de la franja costera de la bahía Blanca (Provincia de Buenos Aires, Argentina) a partir de la visión de sus habitantes
}

A transformação da faixa costeira da baía Blanca (Província de Buenos Aires, Argentina) a partir da visão de seus habitantes

\section{The transformation of the coastal band of the Blanca bay (Province of Buenos Aires, Argentina) from the vision of his inhabitants}

La transformation de la frange côtière de la baie Blanche (Province du Buenos Aires, de l'Argentine) à partir de la vision de seus habitants

\author{
Marian Alwjandra Ramborger* \\ Maria Amália Lorda*
}

Recebido em 23/3/2009; revisado e aprovado em15/5/2009; aceito em 30/7/2009

\begin{abstract}
Resumen: El proceso de ocupación de la franja costera de la bahía Blanca ha derivado en una gran transformación de su medio natural. El objetivo del presente trabajo es analizar la perspectiva que los habitantes del área poseen acerca de los cambios acaecidos en ésta. Para ello se efectuaron cuatro entrevistas en profundidad a personas de la Tercera Edad que vivieron la mayor parte de su vida en la localidad de Ingeniero White, la cual se encuentra ubicada sobre la misma costa.

Palabras clave: Costa. Historia ambiental. Entrevistas en profundidad.
\end{abstract}

Resumo: O processo de ocupação da faixa costeira da baía Blanca derivou de uma grande transformação de seu meio natural. O objetivo do presente trabalho é analisar a perspectiva que os habitantes da área possuem a respeito das mudanças ocorridas nesta. Para isso, foram efetuadas quatro entrevistas em profundidade a pessoas da Terceira Idade que viveram a maior parte de sua vida na localidade de Ingeniero White, a qual se encontra localizada na mesma costa.

Palavras-chave : Costa. História ambiental. Entrevistas em profundidade.

Abstract: The process of occupation of the coastal band of the Blanca bay has derived in a great transformation of its natural way. The aim of the present work is analyze the perspective that the inhabitants of the area possess over of the changes happened in this one. For it, four interviews in depth were effected to persons of the Third Age who lived most of theirs lives in the locality of Ingeniero White, which is located on the same coast.

Key-words: Coast. Environmental history. Interviews in depth.

Résumé: Le processus d'occupation de la frange côtière de la baie Blanca a dérivé dans une grande transformation de son milieu naturel. L'objectif du travail présent est d'analyser la perspective que les habitants de l'aire possèdent à propos des échanges arrivés dans celle-ci. Pour cela quatre interviews dans profondeur ont été effectuées aux personnes du Troisième Âge qui ont vécu la plupart de sa vie dans la localité d'Ingeniero White, qui trouve placée sur la même dépense.

Mots-clés: Dépense. Histoire de l'environnement. Interviews dans profondeur.

\section{Introducción}

La relación que la sociedad establece con la naturaleza varía a través del tiempo de acuerdo al modelo económico y las pautas culturales que prevalecen en cada época. Esto se expresa en el espacio, convirtiéndose éste en un "[...] testimonio de un momento dado de un modo de producción [...], el testigo de un momento del mundo" (SANTOS, 1990, p. 154)

Desde el siglo XIX, ha predominado una racionalidad de tipo económica e instrumental, que prioriza la obtención de ganancias económicas en el corto plazo, revirtiendo sus costos sobre los sistemas naturales y sociales. Como resultado de la misma, se produce una gran crisis ambiental que afecta a nuestro planeta en la actualidad.

En consecuencia, en los últimos años emerge otro concepto con mayor especificidad: el de racionalidad ambiental (LEFF, 1998), que busca la construcción de una racionalidad productiva alternativa, con el objetivo de resolver las irracionalidades propias de la lógica capitalista a partir de principios éticos, bases materiales, instrumentos técnicolegales y acciones políticas y sociales que prioricen el respeto por el medio ambiente.

\footnotetext{
* Professoras de geografia e turismo na Universidade Nacional Del Sur. Bahia Blanca. Argentina. E-mail(s): alejandra.ramborger@uns.edu.ar; malorda@criba.edu.ar.
} 
La historia ambiental, metodología propia de las ciencias ambientales, al analizar los cambios que resultan de sucesivos procesos originados en la relación sociedadnaturaleza, permite entrever las racionalidades que se encuentran tras el accionar de los grupos humanos sobre su entorno.

El objetivo del presente trabajo es, a través del análisis de las entrevistas en profundidad efectuadas a algunos habitantes de la localidad Ingeniero White, vislumbrar la percepción que poseen sobre los cambios acaecidos en la franja costera de la bahía Blanca, con la finalidad de determinar las racionalidades predominantes en el proceso de ocupación de este espacio.

\section{La franja costera de la bahía Blanca}

El área de estudio corresponde a la franja costera del estuario de la bahía Blanca, en el sector comprendido entre la desembocadura del Arroyo Napostá y el Balneario Maldonado. La misma forma parte del partido de Bahía Blanca, localizado en el Suroeste de la provincia de Buenos Aires (Argentina) sobre la costa del océano Atlántico a los $38^{\circ} 44^{\prime}$ de latitud Sur y $62^{\circ}$ $16^{\prime}$ de longitud Oeste (Fig. 1).

La elección del área responde a su importancia para la ciudad de Bahía Blanca y la región, ya que "es el soporte físico del área portuaria industrial, el nodo convergente de la estructura férrea y vial y el asiento de la localidad de Ingeniero White" (TORRE, PASQUALE y GARCIA MUÑOZ, 2006). A esto se agrega que es un espacio interesante para analizar la manifestación de diversos problemas ambientales, en los últimos años.

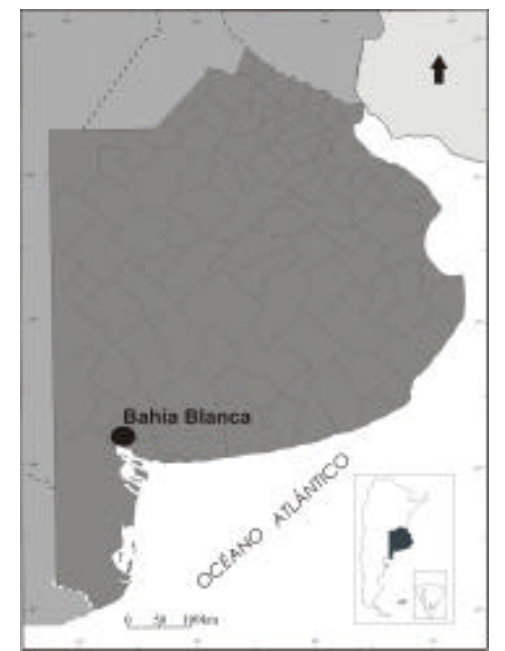

Ciudad de Bahía Blanca y localidad de Ing. White

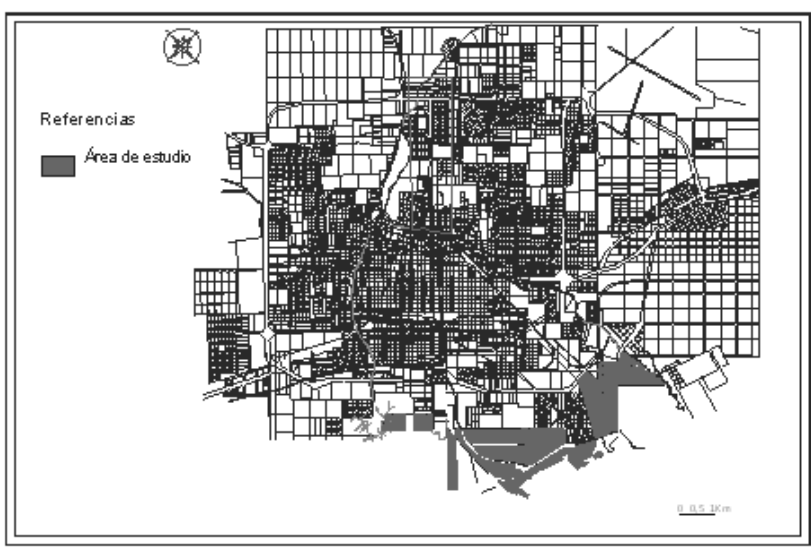

Figura 1 - Localización del área de estudio Fuente: RAMBORGER, M., 2008.

Ingeniero White es un asentamiento poblacional ubicado sobre la misma costa del estuario, que surgió en forma espontánea alrededor del puerto homónimo, creado en 1885. La prosperidad alcanzada por éste promovió la instalación de otro puerto en sus cercanías, Puerto Galván, en 1902, y de diversas industrias, entre las que se destacan la petroquímica y petrolera (Fig. 3).

En cuanto a las condiciones del medio natural de la franja costera de la bahía, es importante mencionar que según se geomorfología se define como llanura costera baja, hasta la cual llega la influencia de los movimientos de las mareas diarias. En cuanto al ambiente marino, domina el estuario de la bahía Blanca. Los suelos se caracterizan por una alta presencia de arcilla, la cual aumenta su espesor hacia el mar.

El sector pertenece al ambiente de humedal, área sujeta a la influencia del agua, en este caso de las mareas. La vegetación correspondiente a la zona costera es el matorral halófilo. El ambiente de planicies de marea y marismas es el dominio de especies pioneras o colonizadoras. Las halófilas 
son las únicas especies que prosperan aquí debido a las adaptaciones que poseen para tolerar el elevado contenido de sales presente en el suelo.

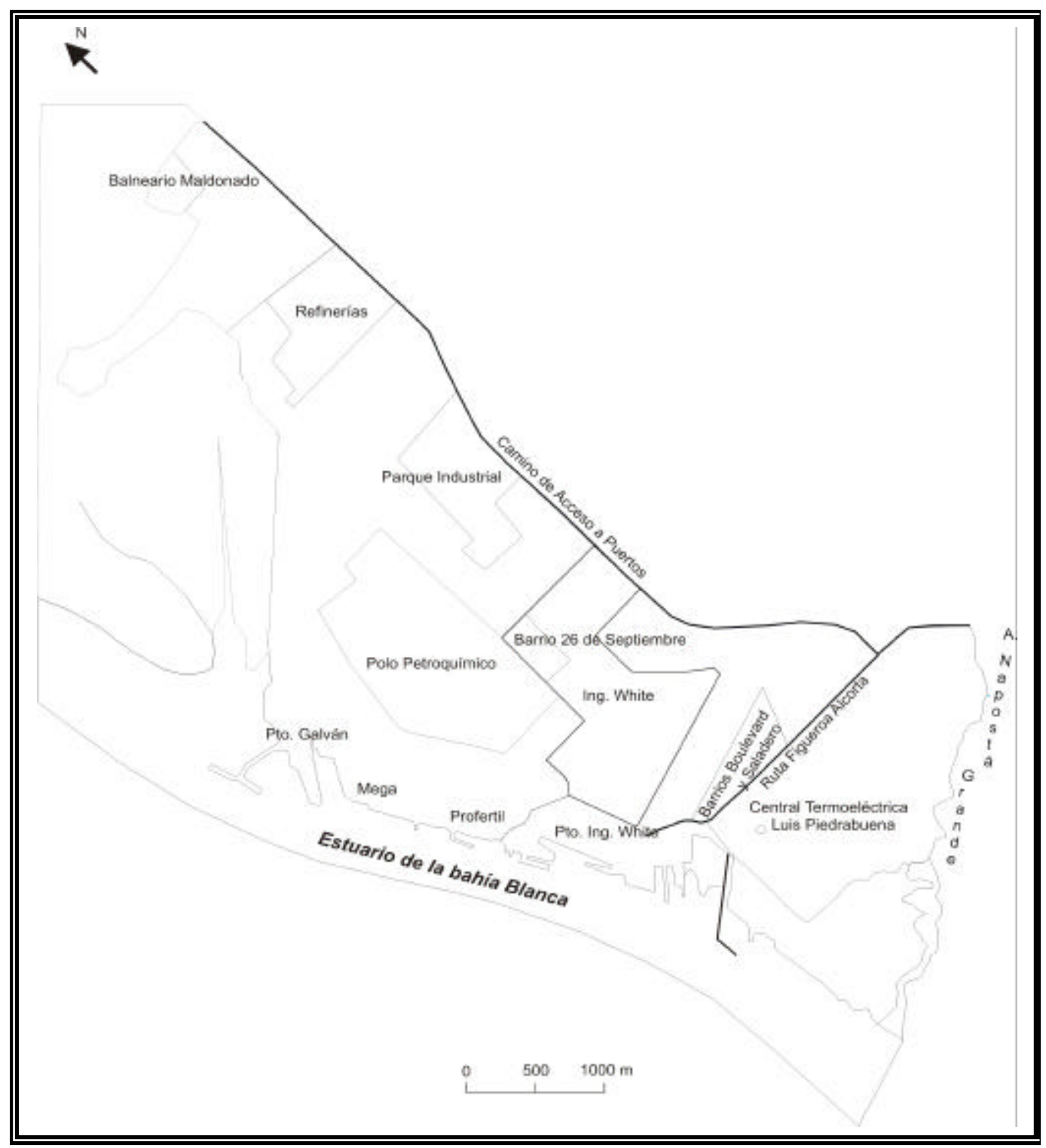

Figura 2 - Localidad de Ingeniero White y alrededores

Fuente: RAMBORGER, M. A., 2008.

\section{Aportes teóricos utilizados para la realización y análisis de las entrevistas}

Para reconstruir la historia ambiental del sector costero entre la desembocadura del arroyo Napostá y el Balneario Maldonado, se recurrió a diversas fuentes histórico-geográficas, que son aquellas que a lo largo del tiempo al ser analizadas por los investigadores adquieren este carácter. Estas son de distinto tipo como puede observarse en la Figura 2. Es fundamental la consulta a múltiples fuentes, ya que esto permite entender la problemática en estudio desde diversas perspectivas. 


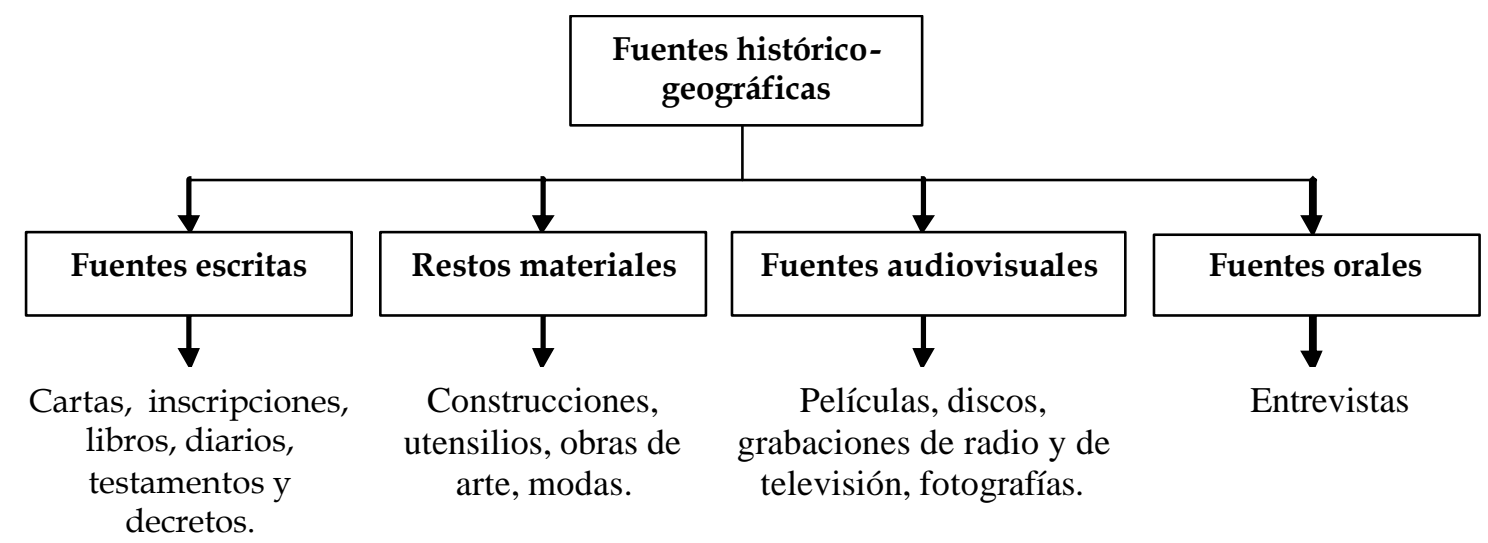

Figura 3 - Fuentes histórico-geográficas

Para la recuperación de los testimonios orales se empleó la técnica de la entrevista en profundidad (TAYLOR y BOGDAN, 1998). Esta se caracteriza por ser flexible y dinámica, es decir, que el investigador cuenta tan sólo con una guía con los temas claves para asegurarse que éstos sean explorados, formulando las preguntas en el mismo momento en que se está llevando a cabo.

Se seleccionaron para realizar las entrevistas a personas dentro del grupo de la Tercera Edad, es decir mayores de 65 años, y que han vivido la mayor parte de sus vidas en la localidad de Ingeniero White, ya que se consideró que esto influye en gran medida en el grado de conocimiento de la temática en estudio.

Al momento de efectuar y analizar las entrevistas, el paradigma de la Geografía Humanista fue un gran aporte, por su enfoque comprensivo de la experiencia vivida por las personas.

Esta corriente se apoya en las nociones propuestas por la fenomenología, que postula que

[...] todo conocimiento procede de la experiencia, del mundo o espacio vivido [...]. $\mathrm{Su}$ objetivo es identificar y describir las experiencias tal como son aprehendidas, además de la subjetividad, intuición, valores y las apariencias directas. (SANTARELLIDE SERER y CAMPOS, 2002, p. 65)

También se basa en las concepciones del existencialismo, que reconoce la temporalidad de la existencia humana y su historicidad. Además, suma los aportes del idealismo, que busca develar aquellos principios que dirigen las acciones humanas.

\section{Recuperando las voces de los actores del área}

A fin de complementar la búsqueda bibliográfica, cartográfica y de fotografías, se efectuaron cuatro entrevistas en profundidad, dos a personas del sexo femenino y dos del sexo masculino, que habitaron la mayor parte de su vida en la localidad de Ingeniero White; con el objeto de escuchar las voces de quienes vivieron la transformación del medio natural del área en forma cercana.

La primera entrevista fue efectuada a una señora del Barrio 26 de Septiembre. Ella y su familia residieron toda su vida en Ingeniero White, $\mathrm{y}$ en el barrio previamente mencionado desde hace veintiocho años. Sin embargo, manifestó desconocer muchos aspectos relativos a la franja costera.

Al hablar del puerto, se notó la influencia ejercida por la visión de progreso, que predominó desde la fundación del puerto y hasta la década del ' 80 del siglo pasado, como se evidencia en la siguiente expresión de la entrevistada: "Todo eso se perdió, pero bueno es el adelanto del mundo". Entre las obras importantes llevadas a cabo en la zona portuaria destacó el muelle de Hierro.

Las diferencias que mencionó respecto a la situación de la franja costera en el pasado y el presente, es la presencia de algunos balnearios hoy ya desaparecidos, como el que se encontraba en Puerto Galván y en cercanías al Boulevard. La utilización de estos era el único motivo por el cual visitaba la franja costera. Otra distinción que hizo fue la edificación incorporada al sector 
en estudio. En la entrevista también aludió a las inundaciones que solían ocurrir en la localidad de Ingeniero White, y más precisamente en el área donde actualmente se encuentra el barrio donde ella habita, a pesar del freno que supuso para las aguas del mar la construcción del terraplén de piedras por parte del ferrocarril. Posteriormente por las diversas edificaciones llevadas a cabo en el área explicó que disminuyó la frecuencia e intensidad de las mismas. Además comentó que se producían inundaciones en el Boulevard, que eran de mayor magnitud debido a la inexistencia de alguna barrera que hiciera de freno a las aguas del estuario.

Cuando se le consultó acerca de los posibles efectos de la transformación del medio natural del área sobre la calidad de vida contestó que ésta no se vio afectada, gracias a los controles llevados a cabo por la Municipalidad. Se notó que existía en la entrevistada cierto temor a contestar, ya que preguntó frecuentemente si esta información no se iba a dar a conocer en la televisión a pesar de que al inicio de la entrevista se aclaró el motivo de la realización de la misma y cuál iba a ser la utilización de los datos provistos durante la conversación.

Se percibió que la entrevistada no tiene una valoración muy positiva acerca del ecosistema de humedal como se puede entrever en sus siguientes palabras: “[...] era un poco desierto $[. . .]^{\prime \prime}$. Esto puede adjudicarse al desconocimiento, ya que acerca de la vegetación dijo que no había. Sobre la fauna, enumeró sólo que había peces presentes en el mar y, después cuando se le consultó acerca del área de cangrejales, recordó su presencia. Al ambiente lo describió como un salitre, lo cual es bastante certero.

Acerca de la necesidad de protección de aquellas áreas que aún no han sido tan transformadas, no respondió porque dijo desconocer la zona más allá del puerto.

La segunda entrevista corresponde también a una persona del sexo femenino, que reside en cercanías del centro de la localidad de Ingeniero White. Esta persona vive desde que nació en este lugar, exceptuando unos años que debió trasladarse por motivos laborales de su padre a otros sitios.

$\mathrm{Al}$ igual que la primera entrevistada, solía ir a la franja costera para disfrutar del balneario que se encontraba en la zona donde actualmente se localiza la empresa Profertil. En la descripción que realizó de la playa mencionó que era un barrial, hasta que llegaba la marea, y que estaba rodeada por tamariscos.

Sobre el puerto comentó que en el pasado era mucho más reducido y destacó la importancia que ejercía en su desarrollo el ferrocarril, principalmente por la playa de ferrocarril existente en éste, que es la más grande del país, según la entrevistada.

$\mathrm{Al}$ ambiente del área, lo describió como muy hermoso, sobre todo visto desde el aire, desde donde se pueden apreciar los riachos y las islas, en donde se pueden hallar conejos y patos. En coincidencia con la señora entrevistada en primera instancia, aludió a la característica salitrosidad del suelo. Otras especies de la fauna que enumeró como propias del ambiente de esta zona son las gaviotas, vizcachas, los peces y los famosos músculos (localismo de moluscos), los cuales en el pasado eran recogidos de los pilares del muelle y empleados para consumo humano. Actualmente no es apta su ingesta, debido a la eliminación de los efluentes cloacales en el estuario. Sobre la vegetación ya presenta una cierta confusión entre aquella que es autóctona y la que ha sido implantada por el hombre, como los tamariscos.

Entre los cambios producidos en el área destaca el relleno del área donde se encontraba el balneario. Cuando se le consultó acerca de los impactos de las diversas obras llevadas a cabo en el área habló acerca de la destrucción que el hombre está realizando de su propio hábitat y se lamentó por el precio que ha tenido el progreso sobre el ambiente, por lo que se percibe en la entrevistada una conciencia medioambiental muy desarrollada. Consideró muy importante brindarle protección a aquellas áreas que aún no han sido totalmente transformadas. En cuanto a las actividades que se podrían llegar a realizar en el área que no produjeran un alto impacto sobre el medio natural propuso la pesca deportiva y el ski acuático.

La tercera entrevista se efectuó a una persona de sexo masculino, que reside en la parte más antigua de Ingeniero White. Este encuentro brindó interesantes aportes ya que 
el entrevistado conoce muy bien el área, debido a que habita en ella desde el año 1945 y a que trabajó gran parte de su vida en los talleres del ferrocarril que se ubican frente a la Usina General San Martín, en cercanías de la actual Central Termoeléctrica Luis Piedrabuena.

Los motivos por los cuales frecuentaba el área eran el paseo por los muelles durante los fines de semana y el aprovechamiento de los balnearios. De estas habituales visitas recuerda que el puerto en el pasado era muy diferente a como se encuentra actualmente. Estaban los elevadores de chapa, los de granos, el anexo y en el muelle de hierro, los barcos carboneros y de madera. En el Muelle Nacional no se encontraban los frigoríficos, tan sólo había dos galpones y los guinches. También agregó que en el área se hallaba la playa de ferrocarril más grande de Sudamérica.

En cuanto a Puerto Galván mencionó que en él había barcos carboneros, cerealeros, petroleros y pesqueros. También se acuerda que había una gran cantidad de depósitos, tanto de cereales como de carnes y de maderas en cercanías del puerto. Las únicas molestias que recuerda que había en aquellos tiempos eran el humo generado por los barcos carboneros y las máquinas a vapor y el ruido provocado por las dragas. Además definió como peligrosos los tanques de almacenaje de YPF que se encontraban en el Puerto de Ingeniero White, en los cuales en una ocasión se originó un incendio. También habló sobre las inundaciones, que frecuentemente azotaban a la población de Ingeniero White en el pasado. Estas llegaban hasta el Boulevard, pero gracias a la construcción de la Ruta Figueroa Alcorta disminuyeron su intensidad.

Sobre los cambios llevados a cabo en el sector en estudio señaló el relleno de terrenos para construir la Usina General San Martín. Esta tarea se realizó además hasta el emplazamiento del edificio de la Aduana, donde actualmente se encuentra el Museo del Puerto, para la construcción del Muelle Nacional. En consecuencia, se perdió el balneario que se emplazaba en este sitio, donde se encuentra actualmente la playa de contenedores y Profertil. Otra modificación del paisaje que especificó fue la construcción de la Central Termoeléctrica, para lo cual debió efectuarse también un relleno de los terrenos.

Uno de los efectos negativos que mencionó, como resultado de las actividades humanas en el sector, fue el resquebrajamiento de las viviendas, fenómeno que se inició en el año 1982 y que aún persiste. El entrevistado lo vinculó con los trabajos de bombeo efectuados en la Central Termoeléctrica. Otras consecuencias de las obras realizadas en la zona en estudio señaladas son la contaminación del estuario, lo cual ha provocado una disminución en la captura de peces; la desaparición de ciertas especies, como los cangrejos, los bichos canastos, las luciérnagas, los cascarudos, entre otras; la disminución de la cantidad de aves, los olores desagradables, los daños ocasionados a la plantas, cambios en el clima y el aumento de personas con asma y alergias. Según el entrevistado, la instalación del Polo Petroquímico, con la cual nunca estuvo de acuerdo, ha disminuido mucho la calidad de vida de la población y ha desvalorizado las viviendas de la localidad. También se mostró en oposición al establecimiento de un barrio en forma tan cercana a éste. Además, manifestó preocupación por el emplazamiento de la planta transportadora de gas en Puerto Galván, por el peligro que conllevaría un escape. Todas estas transformaciones e impactos sobre el medio natural se relacionan, según el entrevistado, con el espíritu mercantilista que ha primado en la sociedad. Aunque mencionó que el escape de cloro acaecido en el año 2000, produjo un cambio en la mentalidad de la población, que ha tomado mayor conciencia sobre la necesidad de preservar el medio ambiente.

El paisaje del área fue caracterizado como muy agradable. Consideró que sería necesario proteger las áreas que aún no han sido tan transformadas, otorgando más financiamiento a la reserva ecológica. Se lamentó que todavía no se haya podido concretar el Parque Almirante Brown en su totalidad, atribuyéndolo a que al ser una propuesta de un gobierno de facto fue luego desechada por los gobiernos democráticos; y también por el encierro del Club Naútico por la playa de contenedores. Como posibles actividades a realizar en el área que no 
perjudiquen el medio ambiente propuso las actividades náuticas y deportivas.

La última entrevista corresponde a una persona del sexo masculino que si bien reside actualmente en la ciudad de Bahía Blanca, vivió hasta hace pocos años en la localidad de Ingeniero White, con la cual continúa ligado debido a su colaboración con entidades de bien público de la misma, como la Sociedad Italiana y de San Silverio. Además, estuvo siempre muy vinculado al quehacer portuario, ya que trabajó en el puerto desde los doce años. Primero, se desempeñó como cadete en el Centro Marítimo, luego como apuntador, pagador, capataz y encargado en diferentes empresas privadas de estibaje hasta que ingresó en la Administración General de Puertos. En este ente fue escalando posiciones hasta que llegó al puesto de administrador en el año 1975. En 1993 con la autonomización del puerto pasó a ocupar el cargo de presidente del Consorcio de Gestión, hasta que se jubiló en el año 1999.

El entrevistado señaló como uno de los cambios más importantes producidos en el área el dragado a cuarenta y cinco pies del canal, que permitió el ingreso de buques de mayor tamaño. El barro extraído durante la realización del mismo se empleó para rellenar el área de Cangrejales, entre el Puerto de Ingeniero White y Galván, que se encontraba por debajo del cero de la marea. De esta manera, se ganaron terrenos al mar, en los cuales se instalaron las plantas industriales de Profertil y Mega y que en el futuro van a albergar instalaciones de la Oleaginosa Moreno y de la empresa cerealera Dreyfus. El impacto principal que a su consideración tuvo el relleno fue la pérdida del balneario. Otra repercusión del dragado fue el descenso de las napas. Estas pasaron de encontrarse tan sólo a diez centímetros de la superficie a hallarse a dos metros. Esto tuvo como consecuencia el resquebrajamiento de las casas.

Otra modificación efectuada en el puerto fue el desmantelamiento del muelle de hierro del Puerto de Ingeniero White, el cual ya no resultaba operativo debido al reemplazo del ferrocarril por los camiones y a que entorpecía el ingreso de los grandes buques al sitio n. 9. Este muelle era el único que tenía cañerías que se conectaban con la planta de almacenaje de YPF, por lo en su lugar se construyó la posta de inflamables en Puerto Galván, cuyos caños se vinculan con las refinerías de ESSO, Petrobras, Shell y Gas del Estado.

La sanción de la Ley de Autonomía de los Puertos en el año 1993 es una de las causas de la gran transformación del puerto en los últimos años del siglo XX. La aplicación de esta normativa permitió atraer un gran número de empresas, ya que por un lado brinda seguridad jurídica. Los contratos pasaron de ser de diez años a ser de cuarenta a cincuenta años, lo que les permite a las firmas tener mayor disponibilidad de tiempo para recuperar la inversión. Por otro lado, al quedar las ganancias en el mismo puerto se pueden invertir en la realización de diversas mejoras que captan la atención de diversas compañías.

Através de los estudios llevados a cabo en el área se descubrió que aquellos muelles que se ubicaban en forma paralela al canal se autodragaban, por lo que todos los muelles empezaron a efectuarse de esta manera. Uno de ellos es el muelle multipropósito en el Puerto de Ingeniero White, una obra de destacada importancia para el entrevistado, ya que permite el atraque de buques de contenedores.

Los conflictos ambientales existentes en el área, el entrevistado los atribuye a la falta de planificación del municipio. Un ejemplo claro de esto es la creación del Barrio 26 de Septiembre, el cual fue erigido en terrenos que se encontraban un metro y medio por debajo del nivel del mar, por lo cual ante un evento de precipitación quedaban cubiertos de agua. Estos fueron rellenados por el municipio, gracias a lo cual los dueños de estas tierras pudieron venderlas a los sindicatos para construir las viviendas. Todo esto se realizó con el permiso de la municipalidad, a pesar de que ya se conocía que a una escasa distancia se iba instalar el Polo Petroquímico.

Otro hecho que lo demuestra es que, a pesar de que el sector de la localidad de Ingeniero White que se encuentra de la Avenida San Martín hacia el mar se encuentra catalogado en Catastro como de uso industrial, se hallan residencias familiares. 
Asimismo, adjudica los problemas ambientales existentes a las presiones que han ejercido algunas empresas para lograr una determinada ubicación. El Consorcio de Gestión del Puerto le había ofrecido a la firma Cargill instalarse en el lugar donde actualmente se encuentra Profertil. Sin embargo, la empresa amenazando con emplazarse en otro puerto, en coincidencia con una época donde había necesidad de crear fuentes de trabajo y de atraer inversiones, logró la ubicación que posee actualmente dentro del Puerto de Ingeniero White, la cual es inadecuada debido a la cercanía con las viviendas.

Por lo expuesto, el entrevistado cree que el gobierno debería comprarles las casas a los habitantes del sector de la Avenida San Martín hacia la costa y del Barrio 26 de Septiembre, de manera que puedan vivir en otro sitio, alejados de la contaminación.

Otras instalaciones que según esta persona deberían trasladarse son las del Club Náutico. Estas en un principio se encontraban emplazadas donde se encuentra el elevador n. 5 del Puerto de Ingeniero White, por lo que al comenzar su construcción debieron reubicarse. La propuesta del entrevistado, que en ese momento se desempeñaba como administrador del puerto, era situarlo en el Balneario Maldonado. Sin embargo, gracias a la afinidad de los responsables del Club Náutico con las autoridades superiores de la Administración General de Puertos, lograron conseguir su localización actual. La construcción del muelle multipropósito y la playa de contenedores hicieron que el Club quedará rodeado por la operatoria portuaria.

En cuanto al Club de Pesca ubicado en Puerto Galván por el momento menciona que no generaría inconvenientes. Sin embargo, la futura instalación de la empresa Dreyfus va a provocar molestias, por la gran cantidad de polvo que genera. La localización de este Club obedece a cesión de un terreno en esta área por la década del sesenta, cuando ni se imaginaba el futuro desarrollo que tendría el puerto.

Las repercusiones que han tenido estas obras en el medio natural del área natural son numerosas. Entre ellas, mencionó el entrevistado la desaparición de los moluscos blancos, que solía haber en la costa, y de los moluscos negros, que se encontraban adheridos a los pilotes del muelle de hierro. Esto lo atribuye a la contaminación, provocada principalmente por los efluentes cloacales y los desechos industriales, que son arrojados al mar sin un tratamiento previo. Estos residuos arrojados al mar impiden asimismo el consumo de los peces que se hallan en el puerto. En cuanto a los efectos sobre la calidad de vida de la población considera que son de tal magnitud que Ingeniero White sólo debería ser un lugar para trabajar no para vivir.

El entrevistado atribuye al medio natural del área una importante riqueza. Si bien en la actualidad se encuentra muy contaminado, es importante destacar la presencia de langostinos. Otras especies que nombró como características del lugar son la pescadilla y el pejerrey. En cuanto a las aves, resaltó la abundancia de gaviotas en el puerto. Los suelos los describió como salitrosos. A pesar que el paisaje de la isla de donde provienen sus ancestros, la isla de Ponza, cuyas costas rocosas son bañadas por aguas cristalinas, le parece mucho más bonito, califica al paisaje del estuario como muy agradable, sobre todo el de los canales más pequeños. Considera que sería necesario brindarle protección a aquellas áreas que aún no han sido totalmente transformadas. Para esto habría que brindarle apoyo logístico y financiero a la gente de la Reserva.

\section{Reflexiones finales}

En las entrevistas efectuadas, sin bien no son representativas de la totalidad de la población de Ingeniero White, se puede observar que el grado de conocimiento acerca del área está muy ligado al género al cual pertenecen los entrevistados. Las actividades desarrolladas en el puerto estaban vedadas a las personas del sexo femenino, lo que repercutió en la amplitud de su saber sobre este lugar. Los motivos de las visitas al área en este caso solían ser únicamente el aprovechamiento de los balnearios. Éstos han desaparecido como consecuencia de la expansión de la infraestructura portuaria e industrial. Este impacto ha sido es la más mencionado en las entrevistas, lo que muestra que los habitantes aún añoran ese contacto más estrecho con la costa. Otros impactos aludi- 
dos en varias oportunidades son la pérdida de ciertas especies como los moluscos, la contaminación del estuario y el resquebrajamiento de las viviendas. La valoración del medio natural del área fue positiva en la mayoría de los casos, considerando en consecuencia que es de especial importancia proteger las áreas que aún no se encuentran totalmente transformadas.

La infravaloración, la desinformación y el predominio de una racionalidad de tipo económica e instrumental han sido las principales razones de la degradación del medio natural del área y la conversión de esté a otros usos. A partir del año 2001, cuando se produjeron los escapes de contaminantes de dos de las plantas que forman parte del Polo Petroquímico, se evidenció un cambio en la importancia concedida a la preservación del medio natural en los habitantes de Ingeniero White. A pesar de ello, la racionalidad ambiental no ha logrado imponerse por la influencia que continúan ejerciendo los intereses económicos existentes en el área. Es por esto que se considera necesario concientizar a la población acerca de la importancia de los humedales a través de campañas de difusión y de la incorporación de esta temática en las instituciones educativas de la localidad.

\section{Referencias}

BRÓNDOLO, Margarita y otros. Geografía de Bahía Blanca. Bahía Blanca: Ed. Encestando, 1994.

CAMPOS, Marta; ZINGER, Susana y SANTARELLI, Silvia. Humedales marítimos costeros en la Bahía Blanca. ¿Un ambiente natural en extinción? En: ACTAS IV CONGRESO ANUAL ASAEC (ASOCIACIÓN ARGENTINA DE ESTUDIOS CANADIENSES) LAS ÁREAS PROTEGIDAS Y LA GENTE. [CD ROM]. Neuquén: Asociación Argentina de Estudios Canadienses, 2003.

CAMPOS, Marta; ZINGER, Susana y SANTARELLI, Silvia. Los humedales en la costa marítima del partido de Bahía Blanca: un paisaje a proteger. En: ACTAS IV CONGRESO ANUAL ASAEC (ASOCIACIÓN ARGENTINA DE ESTUDIOS CANADIENSES) LAS ÁREAS PROTEGIDAS Y LA GENTE. [CD ROM]. Neuquén: Asociación Argentina de Estudios Canadienses, 2003.

CASTRO H., Guillermo. Transformaciones de la Tierra. Una antología mínima de Donald Worster. Panamá: Instituto de Estudios Nacionales de la Universidad de Panamá, 2000.

FERNÁNDEZ, Roberto. La ciudad verde. Manual de Gestión ambiental urbana. Mar del Plata: Universidad Nacional de Mar del Plata, Facultad de Arquitectura Urbanismo y Diseño, Ed. CIAM, 1998.

Teoría y metodología de la gestión ambiental del desarrollo urbano. Mar del Plata: Universidad Nacional de Mar del Plata, Facultad de Arquitectura, Urbanismo y Diseño. Centro de investigaciones ambientales, 1996.

FUENTES, Ana María. Transformación ambiental en el valle inferior del arroyo Napostá Grande. Tesis (Licenciatura en Geografía) - Universidad Nacional del Sur, Departamento de Geografía y Turismo, Bahía Blanca, 2004.

LEFF, Enrique. Sociología y ambiente: Formación socioeconómica, racionalidad ambiental y transformaciones del conocimiento. Barcelona: Ed. Gedisa, 1998.

PERILLO, Gerardo M. E. ¿Por qué Bahía Blanca es un estuario? En: PICCOLO, María Cintia y HOFFMEYER, Mónica S. (Eds.). Ecosistema del Estuario de Bahía Blanca. Bahía Blanca: Instituto Argentino de Oceanografía, 2004, p. 11-19.

REBORATTI, Carlos. Ambiente y sociedad. Conceptos y relaciones. Buenos Aires: Ed. Ariel, 1999.

SANTARELLI DE SERER, Silvia y CAMPOS, Marta. Corrientes epistemológicas, metodología y prácticas en geografía. Propuestas de estudio en el espacio local. Bahía Blanca: Universidad Nacional del Sur, Departamento de Geografía, 2002.

SANTOS, Milton. Por una geografía nueva. Madrid: Espasa, 1990.

TAYLOR, Steven J. y BOGDAN, Robert. Introducción a los métodos cualitativos de investigación: la búsqueda de significados. Barcelona: Ediciones Paidós Ibérica, 1998.

TORRE, Elena; PASQUALE, Juan Carlos y GARCIA MUÑOZ, Carina (Comp.) Impacto del crecimiento del sector industrial químico y petroquímico en la gestión urbana de ciudades portuarias. [CD ROM] Bahía Blanca: Comisión Europea, Programa Urb-al, 2006. 